\title{
Comparison of xylazine and medetomidine as premedicants for cats being anaesthetised with propofol-sevoflurane
}

\author{
A. L. Selmi, G. M. Mendes, B. T. Lins, J. P. Figueiredo, G. R. Barbudo-Selmi
}

\begin{abstract}
The effects of premedicating cats with saline, xylazine or medetomidine before anaesthetising them with propofol-sevoflurane were compared. Twenty-four cats were randomly assigned to three groups of eight to receive either $0.25 \mathrm{ml}$ of saline, $0.50 \mathrm{mg} / \mathrm{kg}$ of xylazine or $0.02 \mathrm{mg} / \mathrm{kg}$ of medetomidine intravenously, and anaesthesia was induced with propofol and maintained with sevoflurane. Medetomidine produced a greater reduction in the induction dose of propofol and fewer adverse postoperative effects than saline or xylazine. Hypoxaemia was observed after induction with propofol in the cats premedicated with saline and xylazine, but not in the cats given medetomidine. The cats treated with medetomidine and xylazine developed profound bradycardia. The blood pressure of the cats premedicated with saline and xylazine decreased, but the blood pressure of the cats premedicated with medetomidine was maintained. The cats premedicated with saline took longer to recover from anaesthesia than the other two groups.
\end{abstract}

Veterinary Record (2005) 157, 139-143

A. L. Selmi, DVM, MS, PhD, Universidade Anhembi Morumbi, Rua

Conselheiro Lafaiete, 64 São Paulo, SP,

03164-110, Brazil

G. M. Mendes, DVM,

B. T. Lins, DVM,

Universidade Estadual

Paulista, Distrito de

Rubião Júnior, Botucatu,

SP, 18618-000, Brazil

J. P. Figueiredo, DVM,

Department of Veterinary

Clinical Sciences, Ohio

State University, 1900

Coffey Road, Columbus, OH 43210, USA

G. R. Barbudo-Selmi, DVM, MS,

SQSW 304, Bloco G apto 107, Brasília, Distrito

Federal, Brazil
XYLAZINE and medetomidine are $\alpha_{2}$-adrenoceptor agonists commonly used in small animal practice (Doherty 1988, Dobromylskyj 1996, Golden and others 1998). Their sedative, analgesic and muscle relaxation properties make them particularly suitable for anaesthetising cats (Steinberg 1989, Tranquilli and Benson 1992). Medetomidine is more selective, more potent and more effective than xylazine; an intramuscular dose of $0 \cdot 18 \mathrm{mg} / \mathrm{kg}$ of medetomidine induced the equivalent sedative effect as an intramuscular dose of 3.0 $\mathrm{mg} / \mathrm{kg}$ of xylazine (Steinberg 1989).

Bradycardia, a decrease in cardiac output and a brief period of hypertension followed by a prolonged decrease in arterial blood pressure are usually observed in cats after the administration of xylazine (Tranquilli and Benson 1992). The respiratory effects of xylazine are variable, but respiratory function often remains virtually unchanged (Short and Bufalari 1999). The cardiopulmonary effects of medetomidine are similar to those of xylazine, although they may be more pronounced (Pypendop and Verstegen 1998, Lamont and others 2001); the administration of medetomidine has been associated with sustained hypertension in cats and dogs (Keegan and others 1995, Dobromylskyj 1996, Golden and others 1998). Both xylazine and medetomidine are excellent for premedicating small animals before they are anaesthetised with several injectable and inhalational anaesthetics (Steinberg 1989, Short and Bufalari 1999, Kuusela and others 2001).

Propofol is a rapid-acting, non-barbiturate intravenous anaesthetic. Its rapid onset and relatively short duration of action makes it an ideal agent for the induction of general anaesthesia (Bufalari and others 1998). Premedication with xylazine or medetomidine has been reported to significantly reduce the dose of propofol required in cats and dogs (Cullen and Reynoldson 1993).

Sevoflurane is a halogenated agent with clinical characteristics similar to isoflurane, but it induces anaesthesia more rapidly, and animals recover from it more quickly than with isoflurane (Mutoh and others 1997). It has been reported to produce an increase in heart rate and a significant reduction in arterial blood pressure (Hikasa and others 1997, Mutoh and others 1997). Like other inhalational agents, it produces a dose-dependent decrease in cardiac output, but at clinically effective concentrations cardiac output is well maintained (Doi and others 1983, Hikasa and others 1997). There is increasing interest in the use of sevoflurane in veterinary medicine (Branson and others 2001), and clinical trials have shown that this volatile anaesthetic agent is effective in cats and dogs (Tzannes and others 2000, Branson and others 2001).

To the authors' knowledge, the cardiorespiratory effects of xylazine or medetomidine, administered as a premedicant before propofol-sevoflurane anaesthesia, have not been investigated in cats. The purpose of this study was therefore to compare the cardiorespiratory effects of premedicating cats undergoing ovariohysterectomy with either xylazine or medetomidine before anaesthesia was induced with propofol and maintained with sevoflurane.

\section{MATERIALS AND METHODS}

Twenty-four adult female cats undergoing an elective ovariohysterectomy and weighing between 3.0 and $4.5 \mathrm{~kg}$ were used. They were all considered to be healthy on the basis of the results of a physical examination, a serum biochemical analysis and a complete blood count. The project was approved by the local institutional care and use committee, and written consent was obtained from the cats' owners before they were used. Food was withheld for 12 hours before anaesthesia was induced. The cats were randomly divided into three groups of eight; the cats in group 1 received $0.25 \mathrm{ml}$ of 0.9 per cent saline, the cats in group 2 received $0.50 \mathrm{mg} / \mathrm{kg}$ of xylazine (Virbaxyl; Virbac do Brasil), and the cats in group 3 received $0.02 \mathrm{mg} / \mathrm{kg}$ of medetomidine (Domitor; Pfizer Animal Health) each administered intravenously. After five minutes, propofol (Propoabbott; Abbott Laboratories) was administered intravenously in small increments over one minute until the trachea could be intubated. Five minutes after endotracheal intubation, anaesthesia was maintained with sevoflurane (Sevorane; Abbott do Brasil) in oxygen, at a fresh gas flow of $200 \mathrm{ml} / \mathrm{kg} /$ minute delivered using a Bain breathing circuit. The cats breathed spontaneously and the vaporiser setting was adjusted to 3.4 per cent, which represents 1.3 times the minimal alveolar concentration (MAC) of sevoflurane in cats (Doi and others 1983). Ten minutes after the administration of sevoflurane, each of the cats was ovariohysterectomised by the same surgeon. At the end of the surgery, the cats were disconnected from the anaesthetic circuit.

The cats' systolic, diastolic and mean arterial blood pressures and arterial haemoglobin oxygen saturation $\left(\mathrm{SpO}_{2}\right)$ were determined six times before premedication with a noninvasive oscillometric multiparametric monitor (Dixtal 2010; Dixtal do Brasil) and the mean value of each variable was calculated. The cats' heart rate was recorded by a lead II ECG 
(ECGPC; Tecnologia Eletrônica Brasileira), and their respiratory rate was measured by observing their chest movements. The cats' rectal temperatures were measured with a digital thermometer (Omrom). The cats' blood pressure was measured by placing a cuff circumferentially around the left antebrachium, with the width of the cuff being approximately 40 per cent of the circumference of the limb. The infrared sensor for the determination of oxygen saturation was placed on the cats' lips during the measurements. Recordings were made before premedication, before induction, five minutes after induction, five minutes after the start of sevoflurane delivery and every 15 minutes thereafter until the end of the period of anaesthesia.

The duration of anaesthesia was defined as the time from the induction of anaesthesia until disconnection from the anaesthetic circuit, and the duration of surgery was defined as the time from the first skin incision until the last suture was placed. The endotracheal tube was removed immediately after the return of the swallowing reflex. The time from discontinuing anaesthesia to the return of the pharyngeal reflex was recorded. All the cats received $0.4 \mathrm{mg} / \mathrm{kg}$ of butorphanol (Torbugesic; Fort Dodge) and $0 \cdot 2 \mathrm{mg} / \mathrm{kg}$ of meloxicam (Movatec; Boehringer Ingelheim) intramuscularly for postoperative analgesia after the endotracheal tube had been removed. The amount of propofol needed for induction was recorded. The quality of anaesthetic induction and recovery were evaluated by recording the incidence of adverse effects, such as myoclonus, apnoea, emesis, cyanosis and excitation.

The cardiorespiratory variables were compared among the drug treatments by means of a one-way analysis of variance for repeated measures, followed by the Tukey test to compare values within and among groups (SAS). The time to the return of the pharyngeal reflex and the effect of premedication on the dose of propofol required for induction were compared by a Student's $t$ test. For all the analyses, values of $\mathrm{P}<0 \cdot 05$ were considered to be significant. The data are given as the mean (sd).

\section{RESULTS}

There were no significant differences between the mean bodyweights, ages, and durations of anaesthesia and surgery of the groups (Table 1). The mean induction dose of propofol was lower in the cats given xylazine than in those given saline and significantly lower in the cats given medetomidine than in the

\begin{tabular}{|c|c|c|c|}
\hline Variable & Saline & Xylazine & Medetomidine \\
\hline Age (months) & $20(6)^{a}$ & $22(4)^{a}$ & $19(7)^{\mathrm{a}}$ \\
\hline Bodyweight (kg) & $3.4(0.5)^{a}$ & $3.8(0.4)^{a}$ & $3.6(0.2)^{a}$ \\
\hline $\begin{array}{l}\text { Amount of propofol } \\
\text { for induction }(\mathrm{mg} / \mathrm{kg})\end{array}$ & $12 \cdot 1(4 \cdot 2)^{a}$ & $8.4(1.6)^{b}$ & $6 \cdot 1(0.6)^{c}$ \\
\hline $\begin{array}{l}\text { Duration of surgery } \\
\text { (minutes) }\end{array}$ & $67(7)^{a}$ & $72(5)^{a}$ & $69(4)^{a}$ \\
\hline $\begin{array}{l}\text { Time to return of } \\
\text { pharyngeal reflex } \\
\text { (minutes) }\end{array}$ & $4.6(1.5)^{a}$ & $2.7(1.3)^{b}$ & $2.9(0.3)^{b}$ \\
\hline
\end{tabular}

a, b, c Mean values of groups with different superscripts are significantly different $(\mathrm{P}<0.05)$

other two groups. The time to the return of the pharyngeal reflex was longer in the cats given saline than in the other groups. During their recovery from surgery, four of the cats treated with saline vomited and six of them sneezed, whereas only one of the cats treated with xylazine vomited and two of them sneezed and none of the cats treated with medetomidine developed these side effects.

The heart rate of the cats treated with saline remained stable throughout, but there was a significant reduction in the heart rate of the cats treated with xylazine or medetomidine during the surgery (Table 2). The respiratory rate of the cats in all three groups decreased significantly in a similar pattern after induction with propofol (Table 2). The $\mathrm{SpO}_{2}$ of the cats treated with saline and xylazine decreased after the induction of anaesthesia but remained stable thereafter, whereas in the cats given medetomidine, the $\mathrm{SpO}_{2}$ did not vary (Table 2). The rectal temperature of the cats in all three groups decreased progressively and became significantly lower than the baseline values after 30 minutes.

Medetomidine produced a transient increase in arterial blood pressure after its administration but the arterial pressure was maintained during the induction and maintenance of anaesthesia. In the cats given saline there was a significant reduction in systolic arterial pressure after the administration of propofol, and the arterial pressure was significantly decreased in the cats given saline and xylazine after 15 minutes (Fig 1).

TABLE 2: Mean (sd) heart rate (HR), respiratory rate (RR) and oxygen saturation $\left(\mathrm{SpO}_{2}\right)$ in groups of eight cats premedicated with saline, xylazine or medetomidine before anaesthesia induced with propofol and maintained with sevoflurane

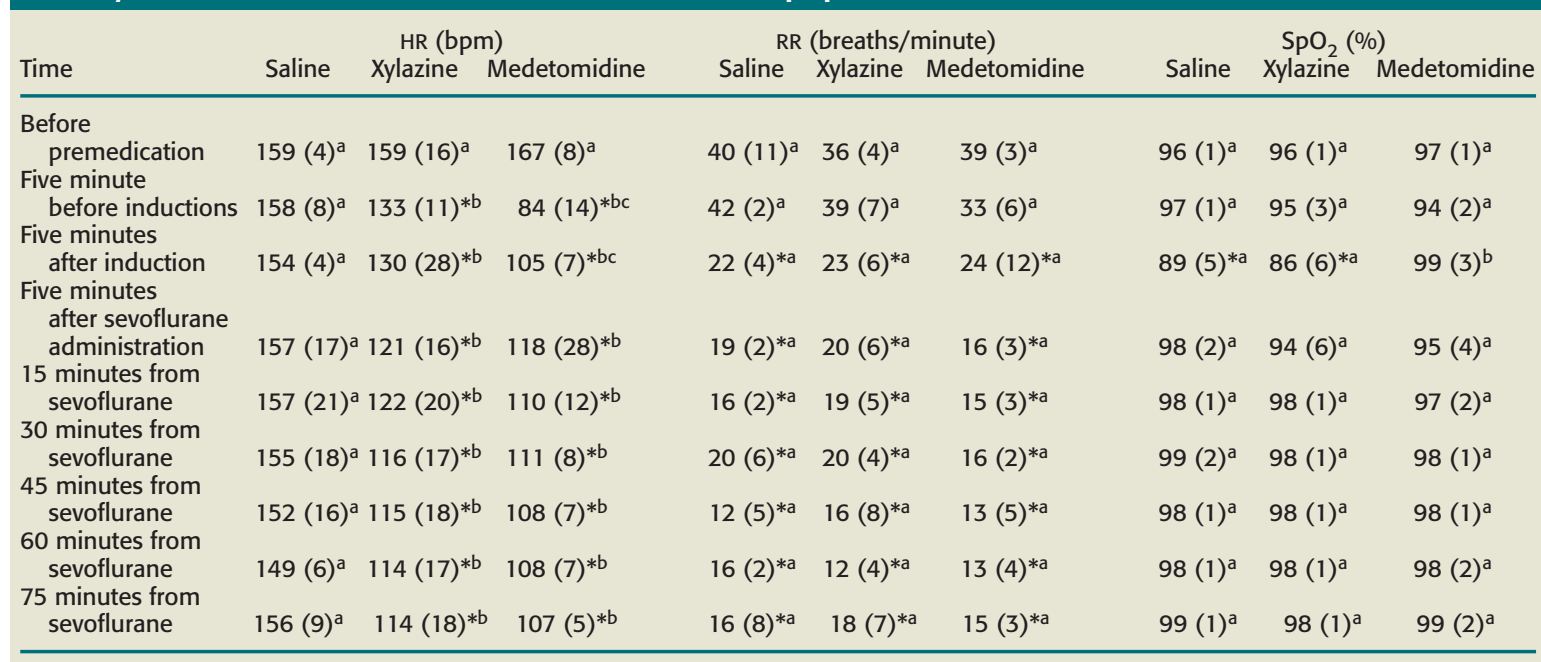

* Significantly different from baseline value $(P<0.05)$; mean values of groups with different superscripts are significantly different $(P<0.05)$ 

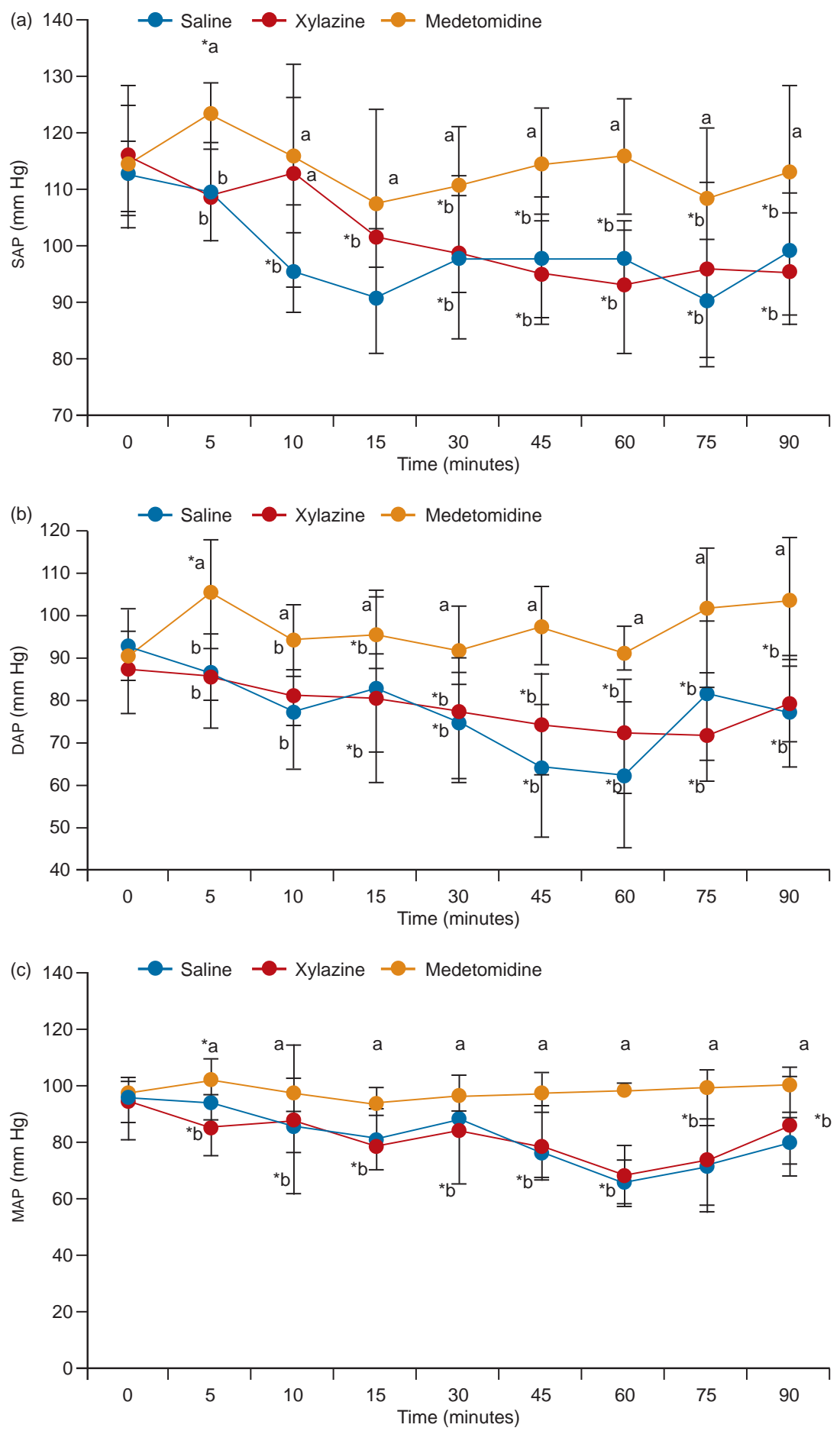

FIG 1: Mean (sd) (a) systolic, (b) diastolic and (c) arterial blood pressure of groups of eight cats premedicated with saline, xylazine or medetomidine before anaesthesia was induced with propofol and maintained with sevoflurane. * Significantly different from baseline value $(P<0.05)$; mean values of groups with different superscripts are significantly different $(\mathbf{P}<\mathbf{0 . 0 5})$

\section{DISCUSSION}

Premedication with either xylazine or medetomidine resulted in a reduction in the dose of propofol required for induction compared with the control group, and the mean dose of propofol required by the cats given medetomidine was significantly lower than that required by the cats given xylazine. This finding may be attributable either to the greater potency and selectivity of medetomidine compared with xylazine, as has previously been observed in dogs premedicated with these $\alpha_{2}$-agonists and anaesthetised with propofol (Cullen and Reynoldson 1993, Short and Bufalari 1999), or to the fact that the dose of medetomidine used was larger than the dose of xylazine, if equipotency is considered.

Sneezing is a common side effect observed in cats after the administration of propofol (Short and Bufalari 1998). Premedication with these $\alpha_{2}$-adrenoceptor agonists minimised the adverse effects of propofol, and the lower incidence of vomiting and sneezing in the cats treated with medetomidine may have been related to the lower induction dose of propofol required by these cats. The induction of anaesthesia with propofol has been associated with a high incidence of apnoea (Cullen and Reynoldson 1993, Short and Bufalari 1999), which appears to be dependent on the dose, the speed of injection and the premedication. The absence of apnoea in the cats in this study was probably due to the administration of the propofol in small increments over one minute, as has been observed in dogs (Kuusela and others 2001).

The cats treated with medetomidine and xylazine recovered more quickly from anaesthesia than the cats treated with saline, and the difference was probably correlated with the reductions in the dose of propofol in these groups.

Significant bradycardia has been reported in cats receiving xylazine and medetomidine, either alone or in combination with other injectable and inhalational anaesthetics (Doherty 1988, Keegan and others 1995, Dobromylskyj 1996, Golden and others 1998, Lamont and others 2001). This characteristic effect is due to a baroreceptor-mediated response to an increase in systemic vascular resistance and to a reduction in CNS sympathetic outflow (Virtanen 1989, Lamont and others 2001). The administration of propofol did not significantly affect the cats' heart rate, as was observed in the cats given saline (Sebel and Lowdon 1989, Short and Bufalari 1999), and the reductions in heart rate observed after the administration of propofol to the cats given xylazine or medetomidine were similar to those described in a study in dogs (Cullen and Reynoldson 1993). Sevoflurane increases or maintains the heart rate unchanged in cats (Hikasa and others 1997), as was observed in the cats pretreated with saline.

Sevoflurane decreases arterial blood pressure as a result of a decrease in systemic vascular resistance (Hikasa and others 1997). In the present study, premedicating the cats with xylazine did not significantly alter their arterial blood pressure, in comparison with the cats given saline, in agreement with previous observations that hypotension can be prevented by the use of low doses of xylazine (Tranquilli and Benson 1992, Short and Bufalari 1999). Unlike xylazine, medetomidine has variable effects on arterial blood pressure, depending on the dose used and whether central or peripheral receptor activation predominates (Pypendop and Verstegen 1998). At low doses, medetomidine has predominantly central effects whereas higher doses produce more stimulation of peripheral adrenoceptors and an intense increase in systemic vascular resistance (Golden and others 1998). The administration of $0.02 \mathrm{mg} / \mathrm{kg}$ of medetomidine did not alter the arterial blood pressure of cats (Lamont and others 2001), but hypertension, even after low doses, has been observed in cats after medetomidine-isoflurane anaesthesia (Keegan and others 1995); however, the exact mechanism by which it occurs is unclear. Golden and others (1998) have suggested that isoflurane anaesthesia may affect the balance between central and peripheral receptor activation, and that the vasoconstrictive effect predominates, resulting in hypertension.

Comparative studies in cats (Hikasa and others 1997) and dogs (Mutoh and others 1997) have shown that sevoflurane and isoflurane induce similar haemodynamic effects, such as hypotension and decreased cardiac output, at comparable anaesthetic concentrations, but in hypovolaemic dogs the depressant effects of sevoflurane on systemic vascular resis- 
tance seem to be more pronounced than the effects induced by isoflurane (Ibañez and others 2002). Thus, the lack of hypertension in the cats given medetomidine in this study could have resulted from the greater depressant effect of sevoflurane on systemic vascular resistance; this suggestion is supported by previous studies reporting hypertension in cats given medetomidine-isoflurane (Keegan and others 1995, Golden and others 1998).

Propofol can cause a depression of respiratory function, usually observed as a decrease in tidal volume and respiratory rate (Sebel and Lowdon 1989, Cullen and Reynoldson 1993). The significant reduction in respiratory rate observed in the cats treated with saline probably represents the effect of propofol and sevoflurane anaesthesia, as previously suggested by Short and Bufalari (1999). These authors have suggested that $\alpha_{2}$-adrenoceptor agonists may substantially aggravate the respiratory depression induced by propofol and inhalational anaesthesia. The decrease in oxygen saturation after the induction of anaesthesia in the cats treated with xylazine and saline was probably due to the higher dose of propofol administered to these cats; the reduction is considered to be clinically important because it could be indicative of mild hypoxaemia. Although cyanosis has been reported in dogs and cats sedated with medetomidine (Virtanen 1989, Pypendop and Verstegen 1998), in this study the oxygen saturation of the cats treated with medetomidine remained unchanged after anaesthesia was induced with propofol.

Cats are more prone to $\alpha_{2}$-adrenoceptor agonist-induced hypothermia than dogs (Doherty 1988). The hypothermia can be attributed either to a decrease in heat production related to the decrease in muscular activity, or to a direct effect on the noradrenergic hypothalamic mechanisms implicated in thermoregulation (Virtanen 1989). In this study similar decreases in rectal temperature were observed in all three groups, but the decreases were probably minimised by the use of a heating pad during the surgery.

The results of this study indicate that in healthy cats medetomidine is more effective than xylazine before the induction and maintenance of anaesthesia with propofol and sevoflurane. The most important adverse effects of adding xylazine to this anaesthetic protocol were a significant reduction in heart rate, and hypotension. Although medetomidine produced a greater reduction in the dose of propofol required for induction, and fewer adverse postoperative effects than xylazine it is at least as safe as xylazine, and both agents should be used cautiously in cats with cardiovascular diseases.

\section{References}

BRANSON, K. R., QUANDT, J. E., MARTINEZ, E. A., CARROLL, G. L., TRIM, C. M., DODAM, J. R., HARTSFIELD, S. M., MATTHEWS, N. S., MACKENTHUM, A. \& BELEAU, M. H. (2001) A multisite case report on the clinical use of sevoflurane in dogs. Journal of the American Animal Hospital Association 37, 420-432
BUFALARI, A., MILLER, S. M., GIANNONI, C. \& SHORT, C. E. (1998) The use of propofol as an induction agent for halothane and isoflurane anaesthesia in dogs. Journal of the American Animal Hospital Association 34, 8491

CULLEN, L. K. \& REYNOLDSON, J. A. (1993) Xylazine or medetomidine premedication before propofol anaesthesia. Veterinary Record 132, 378383

DOBROMYLSKYJ, P. (1996) Cardiovascular changes associated with anaesthesia induced by medetomidine combined with ketamine in cats. Journal of Small Animal Practice 37, 169-172

DOHERTY, T. J. (1988) Physiologic effects of alpha2-adrenergic receptors. Journal of the American Veterinary Medical Association 192, 1612-1614

DOI, M., YUNOKI, H. \& IKEDA, K. (1983) The minimum alveolar concentration of sevoflurane in cats. Journal of the American Veterinary Medical Association 182, 1099-1101

GOLDEN, A. L., BRIGHT, J. M., DANIEL, G. B., FEFEE, D., SCHMIDT, D. \& HARVEY, R. C. (1998) Cardiovascular effects of the $\alpha_{2}$-adrenergic receptor agonist medetomidine in clinically normal cats anesthetized with isoflurane. American Journal of Veterinary Research 59, 509-513

HIKASA, Y., OHE, N., TAKASE, K. \& OGASAWARA, S. (1997) Cardiopulmonary effects of sevoflurane in cats: comparison with isoflurane, halothane, and enflurane. Research in Veterinary Science 63, 205-210

IBAÑEZ, J. F., AULER, J. O. C., Jr \& FIGUEIREDO, L. F. P. (2002) Comparação hemodinâmica e cardiovascular em cães anestesiados com isoflurano e sevoflurano e submetidos a choque hemorrágico. Clínica Veterinária 7, 4650

KEEGAN, R. D., GREENE, S. A. \& BAGLEY, R. S. (1995) Effects of medetomidine administration on intracranial pressure and cardiovascular variables of isoflurane-anesthetized dogs. American Journal of Veterinary Research 56, 193-198

KUUSElA, E., RAEKALliO, M., VÄISÄNEN, M., MYKKANEN, K., ROPPONEN, H. \& VAINIO, O. (2001) Comparison of medetomidine and dexmedetomidine as premedicants in dogs undergoing propofol-isoflurane anesthesia. American Journal of Veterinary Research 62, 1073-1080

LAMONT, L. A., BULMER, B. J., GRIMM, K. A., TRANQUILLI, W. J. \& SISSON, D. D. (2001) Cardiopulmonary evaluation of the use of medetomidine hydrochloride in cats. American Journal of Veterinary Research 62, 1745-1749

MUTOH, T., NISHIMURA, R., KIM, H., MATSUNAGA, S. \& SASAKI, N. (1997) Cardiopulmonary effects of sevoflurane, compared with halothane, enflurane, and isoflurane, in dogs. American Journal of Veterinary Research 58, 885-890

PYPENDOP, B. H. \& VERSTEGEN, J. P. (1998) Hemodynamic effects of medetomidine in the dog: a dose titration study. Veterinary Surgery 27, 612622

SEBEL, P. S. \& LOWDON, M. D. (1989) Propofol: a new intravenous anaesthetic. Anesthesiology 71, 260-270

SHORT, C. E. \& BUFALARI, A. (1999) Propofol anesthesia. Veterinary Clinics of North America: Small Animal Practice 29, 747-778

STEINBERG, D. (1989) Physiologic role of $\alpha_{2}$-adrenoceptors in the regulation of vigilance and pain: Effect of medetomidine. Acta Veterinaria Scandinavica 85, 21-28

TRANQUILLI, W. J. \& BENSON, G. J. (1992) Advantages and guidelines for using alpha-2 agonists as anesthetic adjuvants. Veterinary Clinics of North America: Small Animal Practice 22, 289-293

TZANNES, S., GOVENDIR, M., ZAKI, S., MIYAKE, Y., PACKIARAJAH, P. \& MALIK, R. (2000) The use of sevoflurane in a 2:1 mixture of nitrous oxide and oxygen for rapid mask induction of anaesthesia in the cat. Journal of Feline Medicine and Surgery 2, 83-90

VIRTANEN, R. (1989) Pharmacological profiles of medetomidine and its antagonist, atipamezole. Acta Veterinaria Scandinavica 85, 29-37 


\title{
Veterinary Comparison of xylazine and medetomidine as premedicants for cats being anaesthetised with propofol-sevoflurane
}

\author{
A. L. Selmi, G. M. Mendes, B. T. Lins, et al. \\ Veterinary Record 2005 157: 139-143 \\ doi: 10.1136/vr.157.5.139
}

Updated information and services can be found at:

http://veterinaryrecord.bmj.com/content/157/5/139

\begin{tabular}{cl} 
These include: & $\begin{array}{c}\text { Article cited in: } \\
\text { heferences:/veterinaryrecord.bmj.com/content/157/5/139\#related-urls }\end{array}$ \\
$\begin{array}{c}\text { Email alerting } \\
\text { service }\end{array}$ & $\begin{array}{l}\text { Receive free email alerts when new articles cite this article. Sign up in } \\
\text { the box at the top right corner of the online article. }\end{array}$ \\
\hline
\end{tabular}

Notes

To request permissions go to:

http://group.bmj.com/group/rights-licensing/permissions

To order reprints go to:

http://journals.bmj.com/cgi/reprintform

To subscribe to BMJ go to:

http://group.bmj.com/subscribe/ 